\title{
Intercellular Communication in Spinal Cord Astrocytes: Fine Tuning between Gap Junctions and P2 Nucleotide Receptors in Calcium Wave Propagation
}

\author{
Eliana Scemes, ${ }^{1}$ Sylvia O. Suadicani, ${ }^{1,2}$ and David C. Spray ${ }^{1}$ \\ ${ }^{1}$ Department of Neuroscience, Albert Einstein College of Medicine, Bronx, New York 10461, and 2University Sao Judas \\ Tadeu, Sao Paulo, SP, Brazil
}

\begin{abstract}
Electrophysiological properties of gap junction channels and mechanisms involved in the propagation of intercellular calcium waves were studied in cultured spinal cord astrocytes from sibling wild-type (WT) and connexin43 (Cx43) knock-out (KO) mice. Comparison of the strength of coupling between pairs of WT and Cx43 KO spinal cord astrocytes indicates that twothirds of total coupling is attributable to channels formed by $\mathrm{Cx} 43$, with other connexins contributing the remaining onethird of junctional conductance. Although such a difference in junctional conductance was expected to result in the reduced diffusion of signaling molecules through the $\mathrm{Cx} 43 \mathrm{KO}$ spinal cord syncytium, intercellular calcium waves were found to propagate with the same velocity and amplitude and to the same number of cells as between WT astrocytes. Measurements of calcium wave propagation in the presence of purino-
\end{abstract}

Intercellular propagation of $\mathrm{Ca}^{2+}$ waves has been described in a wide variety of cell types and is considered one mechanism by which cooperative cell activity is coordinated (see Sanderson et al., 1994). In the CNS such waves occur among and between neurons and glial cells both under normal and pathological conditions (Cornell-Bell et al., 1990; Charles et al., 1991, 1996; Cornell-Bell and Finkbeiner, 1991; Cornell-Bell and Williamson, 1993; Attwell, 1994; Kandler and Katz, 1995, 1998; Nedergaard et al., 1995; Takeda et al., 1995; Yuste et al., 1995).

Propagation of $\mathrm{Ca}^{2+}$ waves between cells can be mediated by the intracellular and extracellular diffusion of messenger molecules. Intercellular calcium wave propagation directly from the cytosol of one cell to another requires the presence of gap junction channels, which allow signaling molecules $\left(M_{\mathrm{r}}<1000\right.$ $\mathrm{Da})$, such as inositol triphosphate $\left(\mathrm{IP}_{3}\right), \mathrm{Ca}^{2+}$, and cyclic ADP ribose (Saez et al., 1989; Christ et al., 1992; Churchill and Louis, 1998), to cross boundaries between adjacent cells and thus sustain their propagation. The alternative pathway for communication of the calcium signals involves the diffusion of signaling molecules such as ATP through the extracellular space, activating P2 nucle-

Received Oct. 4, 1999; revised Nov. 30, 1999; accepted Dec. 1, 1999.

This research was supported primarily by the American Paralysis Association, Grant APA SB1-9802-2 (to E.S.), with additional support from the Kirby Foundation (to E.S. and D.C.S.), Fundacao de Amparo a Pesquisa do Estado de Sao Paulo FAPESP 1997/2379-2 (to S.O.S.), and National Institutes of Health 5PO1-NS-07512 and NS-34931 (to E.S., S.O.S., and D.C.S.).

Correspondence should be addressed to Dr. Eliana Scemes, Department of Neuroscience, Room 712, Kennedy Center, Albert Einstein College of Medicine, Yeshiva University, 1410 Pelham Parkway South, Bronx, NY 10461. E-mail: scemes@aecom.yu.edu.

Copyright (C) 2000 Society for Neuroscience $\quad 0270-6474 / 00 / 201435-11 \$ 15.00 / 0$ ceptor blockers indicate that calcium waves in $\mathrm{Cx} 43 \mathrm{KO}$ spinal cord astrocytes are mediated primarily by extracellular diffusion of ATP; measurements of responses to purinoceptor agonists revealed that the functional $\mathrm{P} 2 \mathrm{Y}$ receptor subtype is shifted in the $\mathrm{C} \times 43 \mathrm{KO}$ astrocytes, with a markedly potentiated response to ATP and UTP. Thus, the reduction in gap junctional communication in $\mathrm{C} \times 43 \mathrm{KO}$ astrocytes leads to an increase in autocrine communication, which is a consequence of a functional switch in the P2Y nucleotide receptor subtype. Intercellular communication via calcium waves therefore is sustained in $\mathrm{Cx} 43$ null mice by a finely tuned interaction between gap junctiondependent and independent mechanisms.

Key words: glia; connexin; purinoceptor; calcium waves; spinal cord; connexin43; knock-out mice

otide receptors in neighboring cells that may or may not be in contact (Osipchuk and Cahalan, 1992; Hassinger et al., 1996; Guthrie et al., 1999).

The relative contribution of intercellular gap junctionmediated and extracellular gap junction-independent pathways in the propagation of calcium waves among astrocytes remains controversial. Some reports indicate that the calcium wave spread between astrocytes relies entirely on the gap junction-mediated route (Charles et al., 1992; Finkbeiner, 1992; Nedergaard, 1994; Venance et al., 1995, 1997), whereas others support a pathway involving primarily extracellular ATP diff usion (Hassinger et al., 1996; Guan et al., 1997; Zanotti and Charles, 1997; Cotrina et al., 1998).

Such divergent views regarding the mechanism underlying calcium wave propagation may be related in part to the heterogeneous distribution of gap junctions and P2 receptors in the CNS. Astrocytes from different CNS regions display different degrees of gap junction coupling (Batter et al., 1992; Lee et al., 1994) and express different subtypes of P2 receptors (Pearce and Langley, 1994; Ho et al., 1995; King et al., 1996).

Astrocytes are coupled to each other by gap junction channels formed mainly by connexin 43 (Cx43). In the brain, $\mathrm{Cx} 43$ channels contribute $\sim 95 \%$ of total junctional conductance between astrocytes, with the other connexins (Cx30, Cx40, Cx45, and $\mathrm{Cx} 46)$ supporting the remaining junctional communication (Dermietzel, 1996; Spray, 1996; Spray et al., 1998; Dermietzel et al., 2000; Kunzelmann et al., 1999).

In the spinal cord, although $\mathrm{Cx} 43$ expression has been described between astrocytes (Ochalski et al., 1997; Theriault et al., 1997; Rash and Yasumura, 1999), the relative contribution of 
various connexins to the coupling is unknown. Because differences in connexin expression and in the strength of coupling determine the function and regulation of CNS communication compartments, the present study was undertaken to characterize the gap junction channels and to evaluate the relative contribution of gap junction-dependent and independent mechanisms in the propagation of intercellular calcium waves between spinal cord astrocytes. It is shown here that communication within the spinal cord astrocytic syncytium is sustained by a finely tuned interaction between gap junction-dependent and independent mechanisms, so that a reduction of gap junction-mediated intercellular communication in Cx43 null mice is compensated by an increased autocrine communication. Enhanced intercellular $\mathrm{Ca}^{2+}$ wave signaling in spinal cord astrocytes occurs as a consequence of a functional switch in the $\mathrm{P} 2$ receptor subtype, implying that gap junction and $\mathrm{P} 2$ receptor expression are functionally interconnected.

\section{MATERIALS AND METHODS}

\section{Astrocyte cultures}

Spinal cord astrocytes derived from wild-type (WT) and Cx43 knock-out (KO) neonatal mice (GJA1M1 strain; heterozygotes obtained from Jackson Laboratory, Bar Harbor, ME) were used in this study. After painless death the cervical to lumbar vertebrae were dissected, and spinal cord segments were evicted from the vertebrae with fine forceps. Each spinal cord was cut into small pieces after the removal of meninges and digested in $0.25 \%$ collagenase (Sigma, St. Louis, MO) in PBS, pH 7.4, for 10-20 min at $37^{\circ} \mathrm{C}$. Cells were collected by centrifugation at $1000 \mathrm{rpm}$ for $2 \mathrm{~min}$ at room temperature. The final pellet was suspended in DMEM (Life Technologies, Gaithersburg, MD) containing 5\% fetal bovine serum and $1 \%$ antibiotics, and the cells were seeded on tissue culture dishes. The medium was changed $48 \mathrm{hr}$ later and then every $2 \mathrm{~d}$ thereafter. Astrocytes from the brains of WT and $\mathrm{Cx} 43 \mathrm{KO}$ mice also were used for some experiments. To obtain those cells, we dissected whole brain tissue from neonatal mice after removal of meninges and then minced and incubated them with $0.1 \%$ trypsin at $37^{\circ} \mathrm{C}$. Cells were dissociated from minced tissue by trituration with a small-bore pipette, spun at $1000 \mathrm{rpm}$ for 2 min, and resuspended in culture medium (DMEM) complemented with $5 \%$ fetal bovine serum and $1 \%$ antibiotics and maintained as described above for spinal cord astrocyte cultures. Astrocytes in culture were identified by immunostaining with anti-glial fibrillary acidic protein (GFAP). Approximately $80-90 \%$ of the cells were immunopositive for GFAP. Studies described here were performed on spinal cord and brain astrocytes maintained for 2-3 weeks in culture. Genotypes were determined from PCR of tail samples obtained at the time of cell isolation, as described previously (Dermietzel et al., 2000).

\section{Electrophysiology}

Electrical coupling. Junctional conductance in WT and $\mathrm{Cx} 43 \mathrm{KO}$ spinal cord astrocytes was characterized by using the dual whole-cell voltageclamp technique. Freshly dissociated pairs of astrocytes were voltageclamped at holding potentials of $0 \mathrm{mV}$, and $8-10 \mathrm{sec}$ duration command steps $(\Delta V)$ in $20 \mathrm{mV}$ increments from -110 to $+110 \mathrm{mV}$ or from -100 to $+100 \mathrm{mV}$ were presented to one cell with pClamp 6 software (Axon Instruments, Foster City, CA). Junctional currents $\left(I_{\mathrm{j}}\right)$ were recorded in the unstepped cell; junctional conductance $\left(G_{\mathrm{j}}\right)$ was calculated as $-I_{\mathrm{j}} / \Delta V$ (Spray et al., 1981). Patch pipettes were filled with (in $\mathrm{mm}$ ) $140 \mathrm{CsCl}, 10$ EGTA, and $5 \mathrm{Mg}_{2} \mathrm{ATP}, \mathrm{pH}$ 7.25. Cells were bathed in solution containing (in $\mathrm{mM}$ ) $140 \mathrm{NaCl}, 2 \mathrm{KCl}, 2 \mathrm{CaCl}_{2}, 1 \mathrm{BaCl}_{2}, 2 \mathrm{CsCl}, 1 \mathrm{MgCl}_{2}$, and 5 HEPES, pH 7.2 .

Characterization of gap junction channels. Biophysical properties of junctional channels present between pairs of spinal cord astrocytes were characterized by an analysis of their voltage sensitivity and singlechannel conductances. Voltage sensitivity of $G_{\mathrm{j}}$ was assessed by plotting the ratio of $G_{\mathrm{j}}$ at the end of the pulse (steady-state $G_{\mathrm{j}}$ ) to that measured at the beginning of the pulse (instantaneous $G_{\mathrm{j}}$ ) for each voltage. Unitary junctional conductances were measured in cell pairs in which only a few channels were active by dividing peaks in all-point histograms of junctional currents by the transjunctional voltage $\left(V_{\mathrm{j}}\right)$.

\section{Confocal microscopy}

Intracellular calcium measurements. Confluent cultures of spinal cord astrocytes plated on glass-bottomed microwells were loaded with Indo-1 AM (10 $\mu \mathrm{M}$; Molecular Probes, Eugene, OR) at $37^{\circ} \mathrm{C}$ for $45 \mathrm{~min}$, after which they were rinsed with PBS and used for confocal microscopy. Intracellular $\mathrm{Ca}^{2+}$ was measured in loaded astrocytes bathed in $\mathrm{PBS}, \mathrm{pH}$ 7.4 , at room temperature. The ratio of Indo-1 fluorescence intensity emitted at two wavelengths $(390-440 \mathrm{~nm}$ and $>440 \mathrm{~nm}$ ) was imaged by using UV laser excitation at $351 \mathrm{~nm}$. Ratio images were acquired continuously at $1 \mathrm{~Hz}$ after background and shading correction by using a Nikon real time confocal microscope (RCM 8000) with UV large pinhole and Nikon $40 \times$ water immersion objective (numerical aperture, 1.15; working distance, $0.2 \mathrm{~mm}$ ). Indo-1 fluorescence ratio images were acquired continuously before and 1-2 min after the induction of intercellular calcium waves (see below). The ratiometric images were saved on an optical disk recorder as the average of 32 frames and then played back for measurements of changes in calcium level with Polygon-Star software (Nikon, Tokyo, Japan). The gray levels (number of pixels per area) within the regions of interest (circular spots with radii of $6.4 \mu \mathrm{m}$, containing $\sim 200$ pixels) were averaged and then used for analysis.

Velocity, amplitude, and efficacy of calcium wave spread. Calcium waves in Indo-1 AM-loaded spinal cord astrocytes were evoked by mechanical stimulation of one cell in the confocal field $\left(171 \times 128 \mu \mathrm{m} ; 21,888 \mu \mathrm{m}^{2}\right)$ by a glass pipette with a 1-2 $\mu \mathrm{m}$ outer diameter, as previously described (Scemes et al., 1998). The velocity of calcium waves was calculated as the distance $(\mu \mathrm{m})$ between the stimulated and the nonstimulated cells divided by the time interval $(\mathrm{sec})$ between the half-maximal calcium increases within the stimulated and responding cells. Half-maximal calcium increases were obtained from sigmoidal curves fit to the ascending phase of each Indo-1 fluorescence ratio increase, using Origin 3.01 software.

Amplitudes of calcium wave were considered to be the maximal increments in intracellular calcium observed in responding cells, calculated for each cell as the value of the Indo- 1 fluorescence ratio rise at the peak of the response divided by the basal fluorescence ratio value acquired before the induction of the calcium waves.

The efficacy of calcium spread between glial cells is reported here as the proportion of cells responding with an intracellular calcium increase during the propagation of the wave in relation to the total number of cells within the field of view.

To describe the overall properties of calcium waves under different conditions, we here define a factor (E.V.A.) as being the product of the relative values (test/control) obtained for the Efficacy, Velocity, and $A$ mplitude of the calcium waves.

Contribution of extracellular signaling and gap junction-mediated intercellular communication to the propagation of calcium waves. The contribution of ATP-mediated calcium waves between cultured astrocytes was evaluated by exposing sibling cultures of WT and $\mathrm{Cx} 43 \mathrm{KO}$ spinal cord astrocytes to $100 \mu \mathrm{M}$ of suramin [8-(3-benzamido-4methylbenzamido)naphtalene-1,3,5-trisulfonic acid; Sigma] or PPADS (pyridoxal phosphate-6-azophenyl-2' 4' -disulfonic acid; Sigma), two P2 receptor antagonists (see King et al., 1996; Bolego et al., 1997; Ralevic and Burnstock, 1998), and comparing the velocities, amplitudes, efficacies, and E.V.A. factors of calcium spread with those of untreated cultures.

Heptanol, a potent gap junction channel blocker in astrocytes (Dermietzel et al., 1991), was bath-applied ( $3 \mathrm{~mm}$ final concentration) to astrocytes cultured from both WT and Cx43 KO siblings to measure the effects of gap junction blockade on the calcium wave spread between these glial cells.

\section{Measurements of P2 agonist and antagonist effects}

Intracellular calcium levels. Changes in cytosolic calcium levels induced by $\mathrm{P} 2$ receptor agonists were measured in $\mathrm{WT}$ and $\mathrm{Cx} 43 \mathrm{KO}$ spinal cord and brain astrocytes loaded with fura-2 AM. Cells plated on glass-bottomed microwells were loaded with fura-2 AM (10 $\mu \mathrm{M}$; Molecular Probes) at $37^{\circ} \mathrm{C}$ for $45 \mathrm{~min}$, after which they were rinsed with PBS and viewed on a Zeiss (Oberkochen, Germany) epifluorescence microscope. Intracellular $\mathrm{Ca}^{2+}$ was measured in loaded astrocytes bathed in PBS, $\mathrm{pH}$ 7.4. The ratio of fura- 2 fluorescence emitted at two excitation wavelengths (340 and $380 \mathrm{~nm}$ ) was obtained by using a combined system of an optical filter wheel (Sutter Instruments, Burlingame, CA) and a shutter (Uniblitz, Rochester, NY) driven by an OEI computer (Universal Imaging, Media, PA). The images were acquired with an intensified CCD camera (Quantex) and analyzed with Metafluor Imaging System software (Universal Imaging). Fura-2 fluorescence ratio images were acquired continuously 


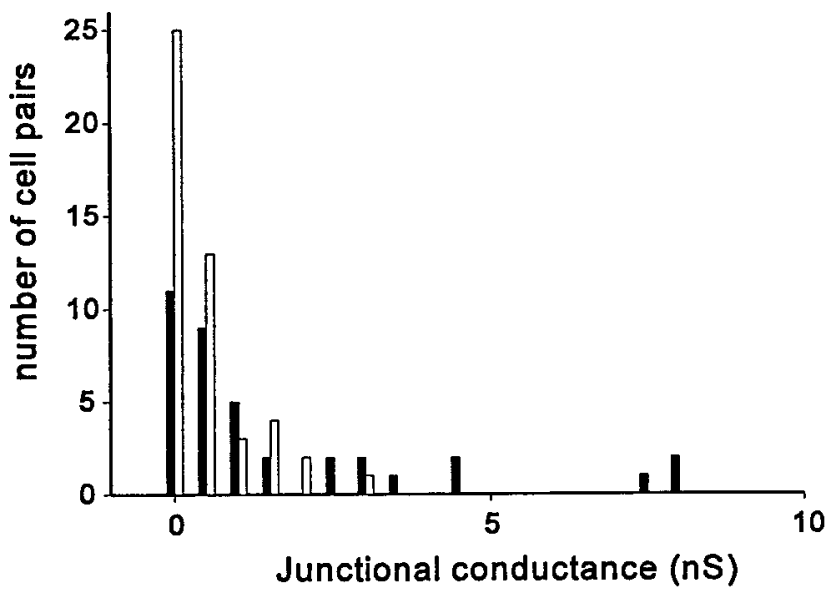

Figure 1. Strength of electrical coupling between cultured wild-type (WT) and Cx43 knock-out (KO) spinal cord astrocytes as determined by dual whole-cell recordings. Measurements of junctional conductance showed that pairs of WT spinal cord astrocytes (black bars) are weakly coupled ( $3.34 \pm 0.94 \mathrm{nS} ; n=43$ cell pairs) and that electrical coupling is significantly lower $(0.94 \pm 0.42 \mathrm{nS} ; n=50$ cell pairs $)$ in $\mathrm{Cx} 43 \mathrm{KO}$ astrocytes (white bars).

at a rate of $0.3 \mathrm{~Hz}$ before and after the addition of purine and pyrimidine receptor agonists. Intracellular calcium levels were obtained by measuring the ratio of fura-2 intensity during excitation at 340 and $380 \mathrm{~nm}$ from regions of interest after using the calibration equation: $\left[\mathrm{Ca}^{2+}\right]_{\mathrm{i}}=K_{\mathrm{D}}$ $\left\{\left(R-R_{\min }\right) /\left(R_{\max }-R\right)\right\}\left(F_{\text {min }}^{380} / F_{\text {max }}^{380}\right)$, where $\left[\mathrm{Ca}^{2+}\right]_{\mathrm{i}}$ is the calculated intracellular calcium concentration, $K_{\mathrm{D}}$ is the dissociation constant of the ion of interest with the dye (in this case $K_{\mathrm{D}}=224 \mathrm{nM}$; Grynkiewicz et al., 1985), $R$ is the ratio intensity, $R_{\min }$ is the ratio of the intensity obtained at zero calcium, $R_{\max }$ is the ratio of the intensity at saturated calcium, $F^{380}{ }_{\min }$ is the fluorescence intensity measured at zero calcium at $380 \mathrm{~nm}$ (nonsensitive to calcium), and $F^{380}{ }_{\max }$ is the fluorescence intensity measured with saturated calcium at $380 \mathrm{~nm}$.

Pharmacology of $P 2$ receptors. Noncumulative dose-response curves were obtained for a series of $\mathrm{P} 2$ receptor agonists on fura-2 AM-loaded astrocytes from brains and spinal cords of WT and $\mathrm{Cx} 43 \mathrm{KO}$ mice. An interval of $5 \mathrm{~min}$ after several washes was maintained between the addition of increasing doses (final concentration, $10 \mathrm{~nm}-1 \mathrm{~mm}$ ) of the same agonist, and a 10 min interval was maintained between two successive curves. After each application the cells were washed three times with $1 \mathrm{ml}$ of PBS. When the effects of P2 antagonists on agonist response were investigated, the antagonists were diluted in PBS and kept in contact with the cells for a period of $15 \mathrm{~min}$ before and throughout the dose-response curve acquisition. The $\mathrm{EC}_{50}$ values (effective concentration that induced half-maximal increase in intracellular $\mathrm{Ca}^{2+}$ levels) for each agonist were calculated from the sigmoidal fittings of the doseresponse curves with Origin 3.01 software. The characterization of the $\mathrm{P} 2$ receptor subtypes involved in the changes in intracellular $\mathrm{Ca}^{2+}$ levels observed in brain and spinal cord $\mathrm{WT}$ and $\mathrm{Cx} 43 \mathrm{KO}$ astrocytes was performed by ranking the $\mathrm{EC}_{50}$ values of the different agonists and comparing the order of potencies with those determined by Ralevic and Burnstock (1998) for each known P2 receptor subtype. The P2 receptor agonists used were ATP, UTP (uridine 5'-triphosphate), 2-Me-S-ATP (2-methylthioadenosine $5^{\prime}$-triphosphate), and ADP- $\beta$-S [adenosine $5^{\prime}-O$ (2-thiodiphosphate]; the $\mathrm{P} 2$ receptor antagonists used were suramin and PPADS.

\section{RESULTS}

\section{Electrical coupling between WT and Cx43 KO spinal cord astrocytes}

Dual whole-cell recordings revealed that junctional conductance between pairs of wild-type spinal cord astrocytes was low (3.34 \pm $0.94 \mathrm{nS} ; n=43$ cell pairs; Fig. 1). However, junctional conductance obtained for pairs of $\mathrm{Cx} 43 \mathrm{KO}$ astrocytes was even lower $(0.94 \pm 0.42 \mathrm{nS} ; n=50$ cell pairs; Fig. 1$)$. These values are statistically different ( $p<0.05$; Student's $t$ test), indicating both
A. wild type

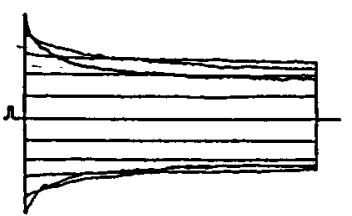

C. wild typo oj

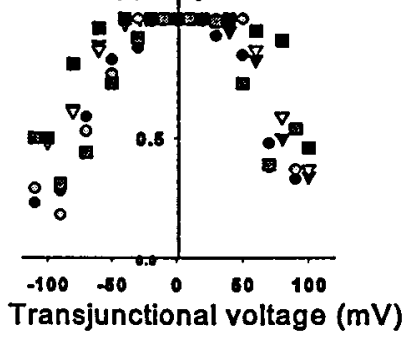

B. $C \times 43 K O$

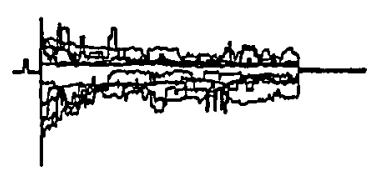

D. $\mathrm{Cx} 43 \mathrm{KO}$

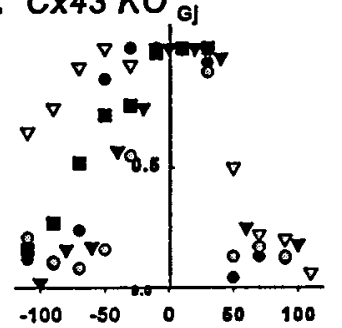

Transjunctional voltage $(\mathrm{mV})$
Figure 2. Voltage sensitivity of junctional conductance $\left(G_{\mathrm{j}}\right)$ between pairs of spinal cord astrocytes from WT $(A, C)$ and from $\mathrm{Cx} 43 \mathrm{KO}(B, D)$ mice. In pairs of WT spinal cord astrocytes, $G_{\mathrm{j}}$ was insensitive to transjunctional voltages below $50 \mathrm{mV}\left(V_{0}= \pm 60 \mathrm{mV}\right)$, and a substantial voltage-insensitive conductance was present even at $80 \mathrm{mV}(A, C)$, indicating that $\mathrm{Cx} 43$ is the dominant protein forming junctional channels. The steeper voltage dependence of the junctional conductance between pairs of $\mathrm{Cx} 43 \mathrm{KO}$ astrocytes $(B)$ indicates that other connexins (most likely $\mathrm{Cx} 40$ and $\mathrm{Cx} 45$ ) contribute to junctional conductance. Different symbols in the graphs represent data points obtained from different cell pairs.

that $\mathrm{Cx} 43$ contributes a major component of junctional conductance and that other connexins also provide gap junctional channels in these cells. Consistent with this finding, voltage sensitivity of $G_{\mathrm{j}}$ in WT and Cx43 KO spinal cord astrocytes differed markedly. In WT astrocytes the relaxation of junctional currents was observed only in response to $50 \mathrm{mV}<V_{\mathrm{j}}<-50 \mathrm{mV}$, whereas in $\mathrm{Cx} 43 \mathrm{KO}$ astrocytes the currents decayed substantially at lower voltages (compare Fig. $2 A, C$ with $2 B, D$ ). In addition, asymmetry was common in $\mathrm{Cx} 43 \mathrm{KO}$ astrocyte cell pairs (see triangles in Fig. $2 B)$, and junctional conductance measured at high voltages $\left(G_{\min }\right.$ or residual conductance; see Spray et al., 1981) was lower for the Cx43 KO than for WT spinal cord astrocytes.

\section{Electrophysiological characterization of gap junction channels expressed in spinal cord astrocytes}

Single-channel recordings obtained from pairs of spinal cord astrocytes revealed differences between WT and Cx43 KO mice. In WT astrocytes, most common junctional channels were 70-90 pS (with a $30 \mathrm{pS}$ substate observed at high $V_{\mathrm{j}}$; Fig. $3 \mathrm{~A}$ ), similar to properties of $\mathrm{Cx} 43$ channels in other systems (Moreno et al., 1994a,b); however, both larger and smaller channels also were detected occasionally (Fig. $3 A, B$ ). In 10 cell pairs in which unitary conductances were resolvable, all pairs exhibited 70-90 pS channels, two showed channels with unitary conductances $>150 \mathrm{pS}$, and two pairs showed 40-50 pS channels. In Cx43 KO spinal cord astrocytes, 30-50 pS channels (Fig. 3C) and larger, $>150 \mathrm{pS}$ channels (Fig. 3D) were predominant. In 10 pairs of $\mathrm{Cx} 43 \mathrm{KO}$ astrocytes, 30-50 pS channels were found in all pairs, and channels with conductances $>150 \mathrm{pS}$ were present in two recordings.

\section{Properties of calcium wave spread between WT and Cx43 KO spinal cord astrocytes}

As a further test for differences in intercellular communication between wild-type and $\mathrm{Cx} 43$ knock-out spinal cord astrocytes, mechanically evoked calcium wave spread was evaluated in these 


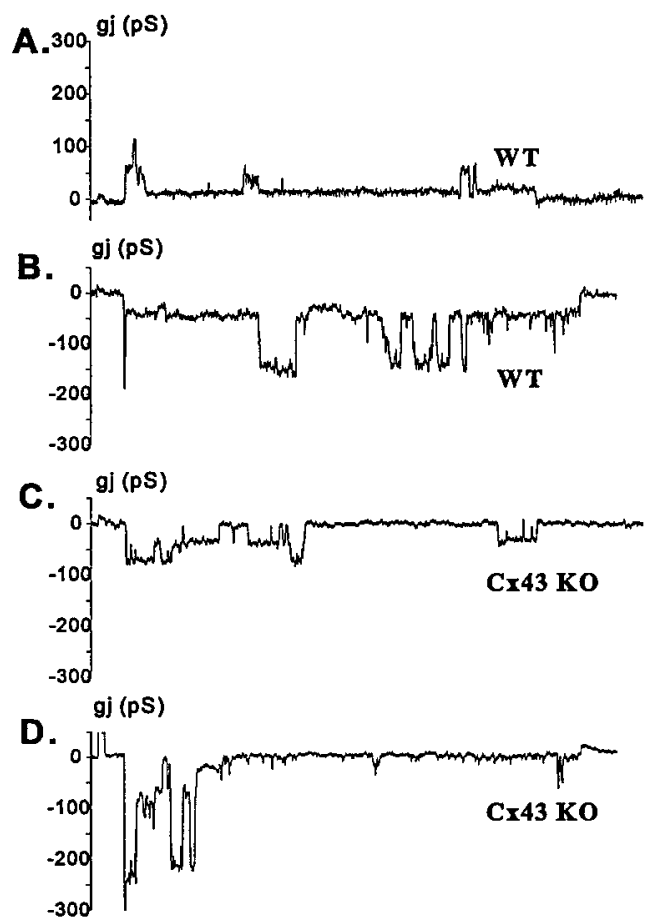

Figure 3. Characteristics of junctional channels between WT $(A, B)$ and $\mathrm{Cx} 43 \mathrm{KO}(C, D)$ spinal cord astrocytes. The channels most frequently observed between pairs of WT astrocytes displayed unitary conductance of $\sim 70-90 \mathrm{pS}(A)$ and showed a $30 \mathrm{pS}$ substate, although $150 \mathrm{pS}$ channels also were seen in $20 \%$ of the recordings $(B)$. In pairs of $\mathrm{Cx} 43 \mathrm{KO}$ astrocytes the most common current fluctuations had sizes corresponding to $30-50 \mathrm{pS}(C)$ without displaying measurable substates; as in WT, large conductance channels $(>150 \mathrm{pS})$ also were observed in $\sim 20 \%$ of the cell pairs $(D)$.

cultures (Figs. $4 A, B, 5 A, D$ ). In response to a brief touch of one astrocyte (indicated in representative examples in Fig. 4A,B), intracellular $\mathrm{Ca}^{2+}$ levels increased in a progressively larger area of the field. For both WT and $\mathrm{Cx} 43 \mathrm{KO}$ spinal cord astrocytes the spread was rapid and extensive (Figs. $4 A_{1}-A_{4} ; 4 B_{1}-B_{4} ; 5 A, D$ ) Measurements of velocity, amplitude, and efficacy of $\mathrm{Ca}^{2+}$ wave propagation are presented in Table 1 and show no significant differences ( $p>0.05$; Student's $t$ test) in any of the parameters; furthermore, the products of these parameters (E.V.A. factor) were very similar, with a ratio near unity.

These data are strikingly different from those previously obtained by our laboratory by using cortical astrocytes (Scemes et al., 1998), in which calcium wave propagation between $\mathrm{Cx} 43 \mathrm{KO}$ cortical astrocytes was shown to be attenuated when compared with that of WT siblings. [For brain astrocytes the ratio of the calculated E.V.A. factors (KO/WT) is 0.46 , indicating that deletion of $\mathrm{Cx} 43$ reduces this overall index of calcium wave propagation by one-half.] To account for such a difference in calcium wave propagation between $\mathrm{Cx} 43 \mathrm{KO}$ spinal cord astrocytes and between $\mathrm{Cx} 43 \mathrm{KO}$ brain astrocytes, we considered three possibilities: (1) that the remaining gap junction channels expressed in Cx43 KO spinal cord astrocytes might be sufficient to allow diffusion of second messengers throughout the syncytium, thereby fully supporting wave propagation in the absence of $\mathrm{Cx} 43$; (2) that the propagation of calcium waves between WT and Cx43 KO spinal cord astrocytes might be an entirely gap junctionindependent mechanism, supported by the diffusion of purines and pyrimidines liberated by the stimulated cells and activating
P2 receptors of the surrounding cells; or (3) that both gap junction-dependent and independent mechanisms might be involved, but that the extracellular component of the calcium wave propagation between $\mathrm{Cx} 43 \mathrm{KO}$ spinal cord astrocytes might be modified in such a way that even small amounts of ATP released from the mechanically stimulated cells would be sufficient to stimulate most cells in the field.

To evaluate the extent to which calcium wave propagation between spinal cord astrocytes from WT and Cx43 KO mice involved gap junction-dependent and independent pathways, we analyzed the properties of calcium wave spread after treating the cells with the gap junction channel blocker heptanol and with two P2 receptor antagonists, suramin and PPADS. Representative examples of each type of experiment are illustrated in Figure 5, and values from all experiments are presented in Table 1.

In both WT and $\mathrm{Cx} 43 \mathrm{KO}$ spinal cord astrocytes bathed in 3 $\mathrm{mm}$ heptanol, the velocity, amplitude, and efficacy of calcium wave propagation were reduced (Fig. $5 B, E$, and $\mathrm{WT}_{\mathrm{h}} / \mathrm{WT}_{\mathrm{c}}$ and $\mathrm{KO}_{\mathrm{h}} / \mathrm{KO}_{\mathrm{c}}$ values in Table 1$)$. However, the reduction was more severe in the WT than in the $\mathrm{Cx} 43 \mathrm{KO}$ spinal cord astrocytes, as reflected by the ratio of E.V.A. factor obtained for each group $\left(\mathrm{KO}_{\mathrm{h}} / \mathrm{WT}_{\mathrm{h}}=5.7\right.$; Table 1$)$. This result indicates that calcium wave propagation in WT spinal cord astrocytes is more vulnerable to inhibition by the gap junction channel blocker than in $\mathrm{KO}$ astrocytes.

The contribution of the extracellular calcium signaling pathway was evaluated by the use of two P2 nucleotide receptor antagonists, suramin and PPADS. In the presence of suramin $(100 \mu \mathrm{M})$ the E.V.A. factor for $\mathrm{WT}$ and $\mathrm{Cx} 43 \mathrm{KO}$ spinal cord astrocytes was reduced to 61 and $50 \%\left(\mathrm{WT}_{\mathrm{s}} / \mathrm{WT}_{\mathrm{c}} ; \mathrm{KO}_{\mathrm{s}} / \mathrm{KO}_{\mathrm{c}}\right.$; bottom part of Table 1$)$, which was primarily attributable to decreased velocity of the waves ( $p<0.001$; Dunn's Method). As a consequence, the ratio of the E.V.A. factor for $\mathrm{WT}$ and $\mathrm{Cx} 43 \mathrm{KO}$ spinal cord astrocytes was close to unity $\left(\mathrm{KO}_{\mathrm{s}} / \mathrm{WT}_{\mathrm{s}}=1.02\right.$; top part of Table 1$)$.

By contrast, in the presence of the $\mathrm{P} 2$ receptor antagonist PPADS $(100 \mu \mathrm{M})$ the calcium waves propagated between $\mathrm{Cx} 43$ $\mathrm{KO}$ astrocytes with an E.V.A. $\left(\mathrm{KO}_{\mathrm{p}} / \mathrm{WT}_{\mathrm{p}}\right)$ factor that was 0.19 of that measured between WT cells in the same condition (Table 1; see also Fig. $5 C, F$ ). Noteworthy, the action of this $\mathrm{P} 2$ antagonist on the propagation of calcium waves between WT astrocytes was minor [E.V.A. $\left(\mathrm{WT}_{\mathrm{p}} / \mathrm{WT}_{\mathrm{c}}\right)=0.86$; see bottom part of Table 1] when compared with the marked attenuation imposed by this agent to the propagation of waves in $\mathrm{KO}$ astrocytes [E.V.A. $\left(\mathrm{KO}_{\mathrm{p}} / \mathrm{KO}_{\mathrm{c}}\right)=0.16$; bottom part of Table 1]. This low E.V.A. factor in $\mathrm{Cx} 43 \mathrm{KO}$ spinal cord astrocytes was attributable both to reduction in velocity and also to a reduced number of cells participating in the response ( $p<0.001$; Dunn's Method; Table 1$)$.

Taken together, these results indicate that both gap junctiondependent and independent mechanisms participate in the propagation of calcium waves between WT and $\mathrm{Cx} 43 \mathrm{KO}$ spinal cord astrocytes. However, the relative contribution of the extracellular pathway to the propagation of intercellular calcium waves differs in these two types of cells; calcium wave spread between WT spinal cord astrocytes is supported mainly by a gap junctiondependent mechanism, whereas waves propagating between $\mathrm{Cx} 43$ KO spinal cord astrocytes are supported mainly by the extracellular component involving diffusion of an agent activating P2 receptors, presumably ATP. Furthermore, because PPADS differently affected wave propagation between WT and KO astrocytes, it was hypothesized that $\mathrm{Cx} 43 \mathrm{KO}$ astrocytes might express a different $\mathrm{P} 2$ receptor subtype that was more sensitive to PPADS blockade than that of the WT cells. 


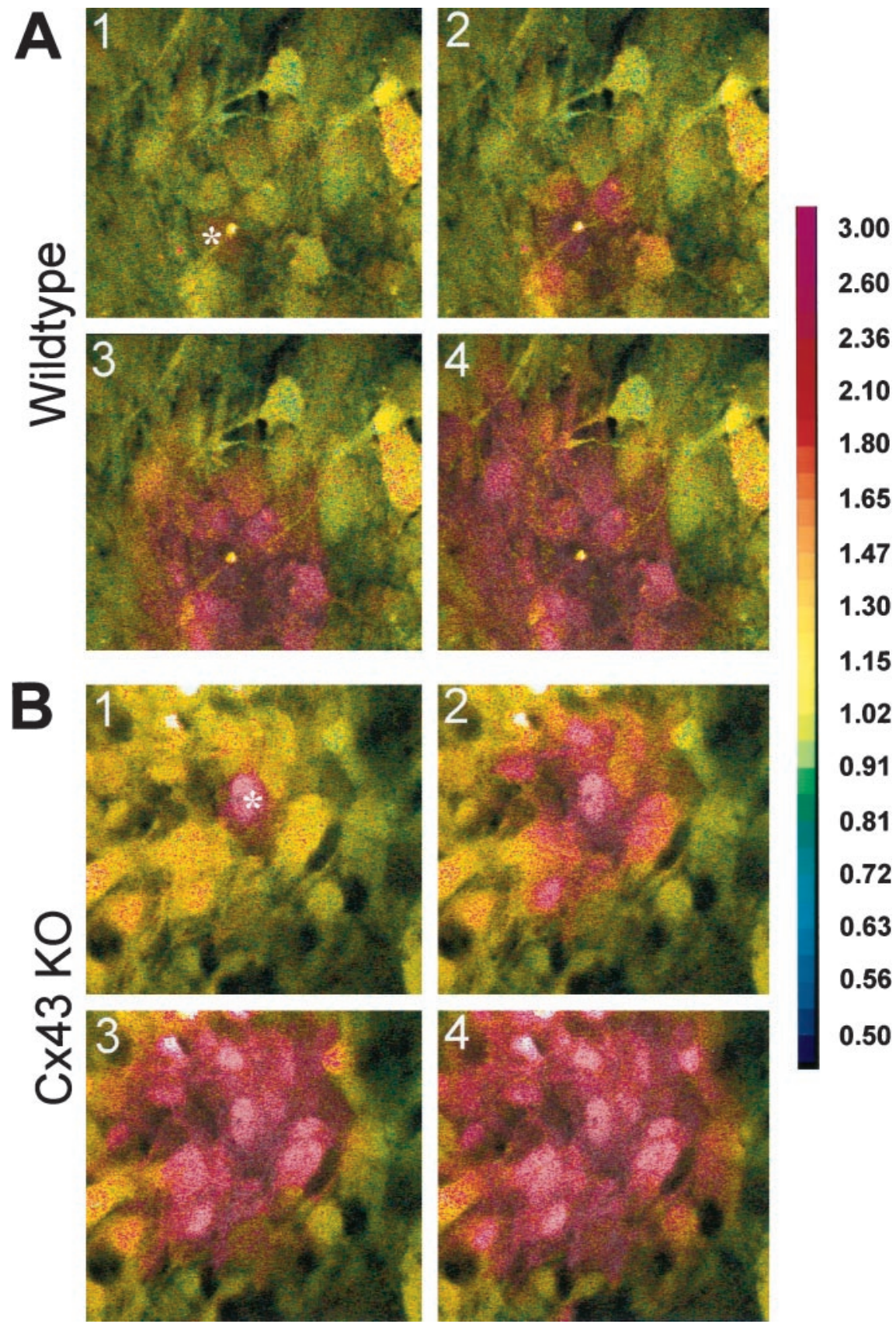

3.00

2.60

2.36

2.10

1.80

1.65

1.47

1.30

1.15

1.02

0.91

0.81

0.72

Figure 4. Intercellular calcium wave propagation in confluent cultures of WT $(A)$ and $\mathrm{Cx} 43 \mathrm{KO}(B)$ spinal cord astrocytes. Cells were loaded with $10 \mu \mathrm{M}$ Indo-1 AM and excited at $352 \mathrm{~nm}$ while being imaged simultaneously at emission wavelengths of 380 and $410 \mathrm{~nm}$, using a Nikon real time confocal microscope. The pseudocolor display shows a range of ratiometrically determined changes in intracellular calcium levels from resting (yellow-green) to high levels (bright red). Images $A_{1}-A_{4}$ and $B_{1}-B_{4}$ were acquired at $1 \mathrm{sec}$ intervals after a single cell (marked by a white cross) was stimulated mechanically during the ratiometric confocal imaging. The pseudocolor scale for Indo-1 fluorescence ratio (from 0.5 to 3.0) is displayed at the right side of the figure.
Because it has been shown that anandamide and oleomide abolish dye and electrical coupling without affecting the calcium wave propagation (Guan et al., 1997), whereas $18 \beta$-glycyrrhetinic acid and heptanol block both gap junction coupling and calcium wave propagation, it was proposed that heptanol and $18 \beta$ glycyrrhetinic acid might block the extracellular component of the calcium waves (Guan et al., 1997). To determine the extent to which heptanol affected the extracellular component of calcium wave propagation in our studies, we incubated astrocytes with 3 mM heptanol, and ATP (5 $\mu \mathrm{M}$; near the $\mathrm{EC}_{50}$ value determined from dose-response experiments shown below) was applied to the cells. As shown in Figure 6, heptanol neither prevented nor attenuated intracellular calcium rise in response to $5 \mu \mathrm{M}$ ATP (Fig. 6B), whereas the P2 antagonist suramin (100 $\mu \mathrm{M})$ totally abolished the response to this same concentration of ATP (Fig.
$6 C)$. ATP sensitivity was fully restored by rinsing the cells for 5 min in PBS (Fig. 6D).

\section{Pharmacological characterization of $\mathbf{P} 2$ receptors in WT and Cx43 KO spinal cord astrocytes}

To determine whether $\mathrm{Cx} 43 \mathrm{KO}$ spinal cord astrocytes express a different $\mathrm{P} 2$ receptor subtype from those of their WT sibling cells, we examined the order of potency of $\mathrm{P} 2$ receptor agonists by measuring the changes in intracellular calcium levels in fura-2 AM-loaded WT and Cx43 KO astrocytes.

The application of increasing concentrations of different P2 receptor agonists to cultured $\mathrm{WT}$ and $\mathrm{Cx} 43 \mathrm{KO}$ spinal cord astrocytes induced dose-dependent increases in intracellular calcium concentration (Figs. 7, 8A, Table 2). Figure 7 shows repre- 


\begin{tabular}{|c|c|c|c|c|c|}
\hline Genotypes & $\begin{array}{l}\text { Velocity } \\
(\mu \mathrm{m} / \mathrm{sec})\end{array}$ & $\begin{array}{l}\text { Amplitude } \\
\text { (folds) }\end{array}$ & $\begin{array}{l}\text { Efficacy (number } \\
\text { of cells) }\end{array}$ & E.V.A. & $n$ \\
\hline $\mathrm{WT}_{\mathrm{c}}$ & $21.23 \pm 0.60$ & $1.60 \pm 0.02$ & $0.93 \pm 0.03$ & & 570 \\
\hline $\mathrm{KO}_{\mathrm{c}}$ & $23.09 \pm 0.99$ & $1.59 \pm 0.02$ & $0.89 \pm 0.04$ & & 339 \\
\hline $\mathrm{KO}_{\mathrm{c}} / \mathrm{WT}_{\mathrm{c}}$ & 1.09 & 0.99 & 0.96 & 1.04 & \\
\hline $\mathrm{WT}_{\mathrm{h}}$ & $6.21 \pm 1.02$ & $1.31 \pm 0.05$ & $0.29 \pm 0.09$ & & 22 \\
\hline $\mathrm{KO}_{\mathrm{h}}$ & $15.06 \pm 2.10$ & $1.32 \pm 0.05$ & $0.67 \pm 0.09$ & & 82 \\
\hline $\mathrm{KO}_{\mathrm{h}} / \mathrm{WT}_{\mathrm{h}}$ & 2.43 & 1.01 & 2.31 & 5.67 & \\
\hline $\mathrm{WT}_{\mathrm{s}}$ & $14.20 \pm 1.49$ & $1.35 \pm 0.04$ & $1.00 \pm 0.65$ & & 117 \\
\hline $\mathrm{KO}_{\mathrm{s}}$ & $12.15 \pm 1.47$ & $1.50 \pm 0.04$ & $0.89 \pm 0.05$ & & 47 \\
\hline $\mathrm{KO}_{\mathrm{s}} / \mathrm{WT}_{\mathrm{s}}$ & 0.86 & 1.11 & 0.89 & 1.02 & \\
\hline $\mathrm{WT}_{\mathrm{p}}$ & $24.83 \pm 1.13$ & $1.37 \pm 0.19$ & $0.82 \pm 0.08$ & & 153 \\
\hline $\mathrm{KO}_{\mathrm{p}}$ & $8.43 \pm 1.10$ & $1.59 \pm 0.04$ & $0.39 \pm 0.20$ & & 118 \\
\hline $\mathrm{KO}_{\mathrm{p}} / \mathrm{WT}_{\mathrm{p}}$ & 0.34 & 1.16 & 0.48 & 0.19 & \\
\hline $\mathrm{WT}_{\mathrm{c}}$ & $21.23 \pm 0.60$ & $1.60 \pm 0.02$ & $0.93 \pm 0.03$ & & 570 \\
\hline $\mathrm{WT}_{\mathrm{h}}$ & $6.21 \pm 1.02$ & $1.31 \pm 0.05$ & $0.29 \pm 0.09$ & & 22 \\
\hline $\mathrm{WT}_{\mathrm{h}} / \mathrm{WT}_{\mathrm{c}}$ & 0.29 & 0.82 & 0.30 & 0.07 & \\
\hline $\mathrm{WT}_{\mathrm{c}}$ & $21.23 \pm 0.60$ & $1.60 \pm 0.02$ & $0.93 \pm 0.03$ & & 570 \\
\hline $\mathrm{WT}_{\mathrm{s}}$ & $14.20 \pm 1.49$ & $1.35 \pm 0.04$ & $1.00 \pm 0.65$ & & 117 \\
\hline $\mathrm{WT}_{\mathrm{s}} / \mathrm{WT}_{\mathrm{c}}$ & 0.67 & 0.84 & 1.09 & 0.61 & \\
\hline $\mathrm{WT}_{\mathrm{c}}$ & $21.23 \pm 0.60$ & $1.60 \pm 0.02$ & $0.93 \pm 0.03$ & & 570 \\
\hline $\mathrm{WT}_{\mathrm{p}}$ & $24.83 \pm 1.13$ & $1.37 \pm 0.19$ & $0.82 \pm 0.08$ & & 153 \\
\hline $\mathrm{WT}_{\mathrm{p}} / \mathrm{WT}_{\mathrm{c}}$ & 1.17 & 0.86 & 0.85 & 0.86 & \\
\hline $\mathrm{KO}_{\mathrm{c}}$ & $23.09 \pm 0.99$ & $1.59 \pm 0.02$ & $0.89 \pm 0.04$ & & 339 \\
\hline $\mathrm{KO}_{\mathrm{h}}$ & $15.06 \pm 2.10$ & $1.32 \pm 0.05$ & $0.67 \pm 0.09$ & & 82 \\
\hline $\mathrm{KO}_{\mathrm{h}} / \mathrm{KO}_{\mathrm{c}}$ & 0.65 & 0.83 & 0.75 & 0.40 & \\
\hline $\mathrm{KO}_{\mathrm{c}}$ & $23.09 \pm 0.99$ & $1.59 \pm 0.02$ & $0.89 \pm 0.04$ & & 339 \\
\hline $\mathrm{KO}_{\mathrm{s}}$ & $12.15 \pm 1.47$ & $1.50 \pm 0.04$ & $0.89 \pm 0.05$ & & 47 \\
\hline $\mathrm{KO}_{\mathrm{s}} / \mathrm{KO}_{\mathrm{c}}$ & 0.53 & 0.94 & 1.01 & 0.50 & \\
\hline $\mathrm{KO}_{\mathrm{c}}$ & $23.09 \pm 0.99$ & $1.59 \pm 0.02$ & $0.89 \pm 0.04$ & & 339 \\
\hline $\mathrm{KO}_{\mathrm{p}}$ & $8.43 \pm 1.10$ & $1.59 \pm 0.04$ & $0.39 \pm 0.20$ & & 118 \\
\hline $\mathrm{KO}_{\mathrm{p}} / \mathrm{KO}_{\mathrm{c}}$ & 0.37 & 0.99 & 0.44 & 0.16 & \\
\hline
\end{tabular}

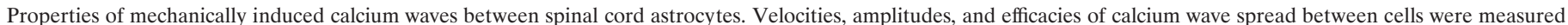

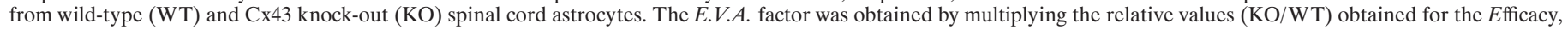

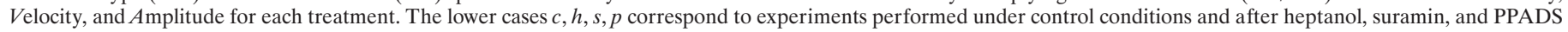

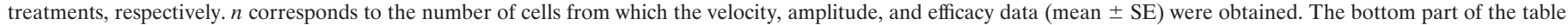

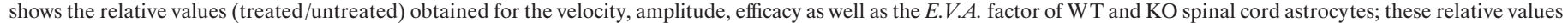
were calculated from the mean values listed in the top part of the table.

sentative results obtained for WT spinal cord astrocytes exposed to different concentrations of ATP, with minimal effective ATP concentrations estimated to be in the range of $1.0 \mu \mathrm{M}$ and maximal responses being induced by $100 \mu \mathrm{M}$ ATP. The doseresponse curves and respective $\mathrm{EC}_{50}$ values obtained for the $\mathrm{P} 2$ receptor agonists in WT spinal cord astrocytes are shown in Figure $8 \mathrm{~A}$. Based on the $\mathrm{EC}_{50}$ values, the responses of WT spinal cord astrocytes to the $\mathrm{P} 2$ agonists could be ranked in the following order of potency: 2 -Me-S-ATP $>$ ATP $>$ UTP $\geq$ ADP- $\beta-S$. Similar to what was described previously for rat spinal cord astrocytes (Salter and Hicks, 1994, 1995), the order of potency obtained here for WT mouse spinal cord astrocytes suggests a predominant participation of the P2Y1 receptor subtype in eliciting rises in intracellular calcium. The possible involvement of the $\mathrm{P} 2 \mathrm{X}$ receptor subtype, which is sensitive to $2-\mathrm{Me}-\mathrm{S}$-ATP, was ruled out in experiments in which application of the specific $\mathrm{P} 2 \mathrm{X}$ agonist, $\alpha, \beta$-Me-S-ATP $(0.1 \mu \mathrm{M}-1.0 \mathrm{~mm})$, did not induce any change in the intracellular calcium levels of these cells $(n=20$; data not shown).

A dramatically different response to $\mathrm{P} 2$ receptor agonists was obtained for $\mathrm{Cx} 43 \mathrm{KO}$ spinal cord astrocytes (Fig. 8B, Table 2). Whereas $\mathrm{EC}_{50}$ values were similar for ADP- $\beta-S$ in WT and $\mathrm{Cx} 43$ $\mathrm{KO}$ spinal cord astrocytes, the $\mathrm{KO}$ astrocytes were markedly more sensitive to ATP and UTP and markedly less sensitive to 2-Me-S-ATP (Fig. 8A,B, Table 2). This resulted in a shift in the order of potency of $\mathrm{P} 2$ receptor agonists $(\mathrm{ATP}=\mathrm{UTP} \gg$ ADP- $\beta-S \geq 2$-Me-S-ATP) obtained for $\mathrm{Cx} 43 \mathrm{KO}$ spinal cord astrocytes, suggesting that these cells express the P2Y2 type as the dominant $\mathrm{P} 2$ receptor.

These results thus indicate that in spinal cord astrocytes lacking $\mathrm{Cx} 43$ there is a change in $\mathrm{P} 2$ receptor subtype from a $\mathrm{P} 2 \mathrm{Y} 1$ to a P2Y2 subtype. It is noteworthy that, besides the change in the order of potency, the concentration of ATP and UTP necessary to induce a half-maximal calcium rise was decreased by one and two orders of magnitude, respectively, in $\mathrm{Cx} 43 \mathrm{KO}$ spinal cord astrocytes $\left(\mathrm{EC}_{50}=0.5 \mu \mathrm{M}\right.$ for both ATP and UTP) as compared with WT siblings $\left(\mathrm{EC}_{50}=4.0 \mu \mathrm{M}\right.$ for ATP; $\mathrm{EC}_{50}=32.0 \mu \mathrm{M}$ for UTP). These data indicate that, in contrast to their WT siblings, Cx43 KO spinal cord astrocytes are substantially more sensitive to these two endogenous nucleotides (Table 2). 

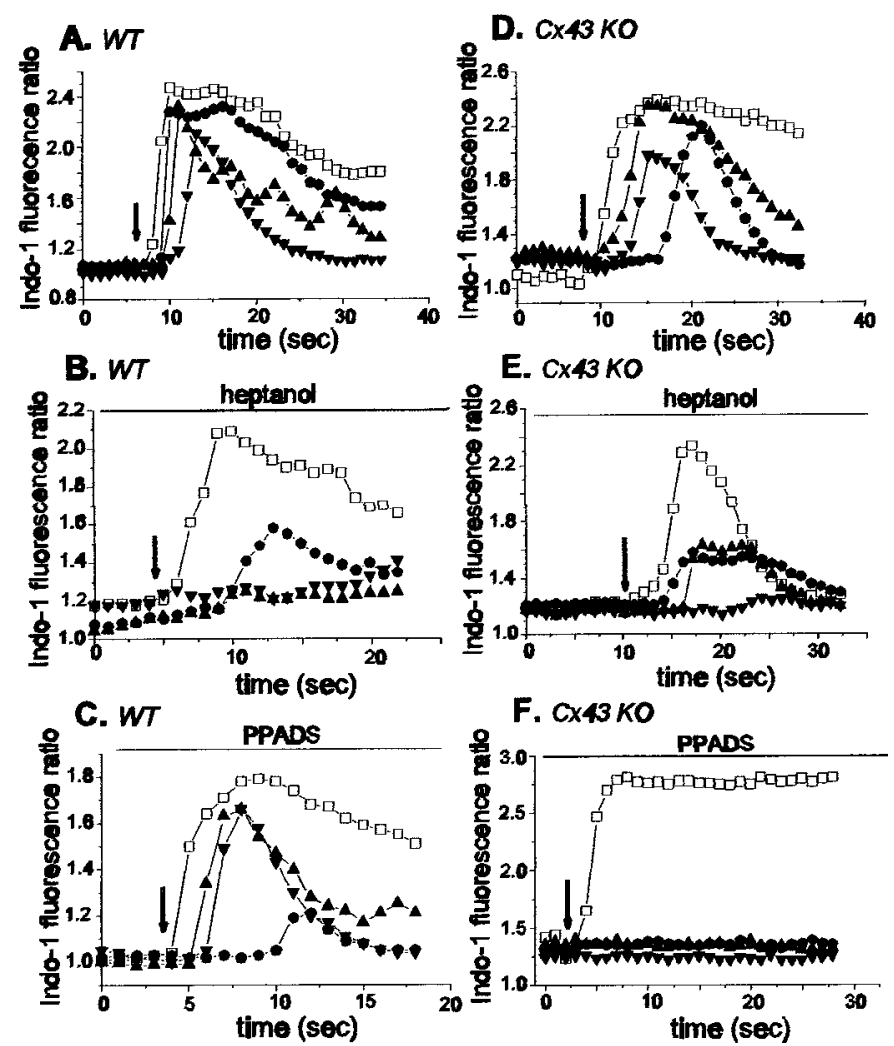

E. $C \times 43 k 0$
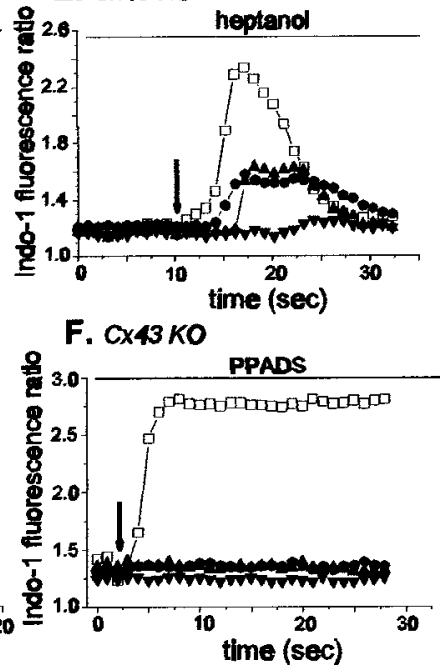

Figure 5. Propagation of calcium waves between cultured WT $(A-C)$ and $\mathrm{Cx} 43 \mathrm{KO}(D-F)$ spinal cord astrocytes under control conditions $(A$, $D)$ and in the presence of heptanol $(B, E)$ and PPADS $(C, F)$. Changes in the Indo-1 fluorescence ratio recorded in the mechanically stimulated cell (open squares) and in three other cells (located no further than $60 \mu \mathrm{m}$ from the stimulated cell; closed symbols) are plotted as a function of time. Note that heptanol greatly attenuated the propagation of calcium waves between WT spinal cord astrocytes $(B)$ and that PPADS blocked the spread of calcium signaling between $\mathrm{Cx} 43 \mathrm{KO}$ spinal cord astrocytes $(F)$. Arrows indicate the time at which a cell was stimulated mechanically; the time interval between the responses of the stimulated cell and other cells was used to calculate the velocity of calcium wave propagation (see Materials and Methods).

\section{Effects of suramin and PPADS on the ATP responses of WT and Cx43 KO spinal cord astrocytes}

Exposure of WT and Cx43 KO spinal cord astrocytes to either suramin $(100 \mu \mathrm{M})$ or PPADS $(100 \mu \mathrm{M})$ greatly reduced the responses induced by ATP (Table 2). However, the antagonism imposed by these two P2 receptor blockers to ATP action was more pronounced in $\mathrm{Cx} 43 \mathrm{KO}$ spinal cord astrocytes than in WT cells (Fig. 8C,D, Table 2). This difference was particularly marked for PPADS, which at $100 \mu \mathrm{M}$ was eightfold more potent in blocking ATP responses of Cx43 KO spinal cord astrocytes (Table 2). Such a difference presumably accounts for the greater inhibition of $\mathrm{Ca}^{2+}$ wave propagation by PPADS than by suramin in Cx43 KO spinal cord astrocytes (see Table 1).

In WT spinal cord astrocytes suramin and PPADS significantly reduced the maximal response induced by ATP (from 4.1 to 0.4 $\mu \mathrm{M} \mathrm{Ca}{ }^{2+}$; Table 2) without affecting the $\mathrm{EC}_{50}$ values (Fig. $7 C$ ), providing evidence that the antagonism is noncompetitive. For Cx43 KO spinal cord astrocytes, however, PPADS was more potent than suramin in reducing the maximal response to ATP (from 1.9 to $0.1 \mu \mathrm{M} \mathrm{Ca}^{2+}$ and to $0.3 \mu \mathrm{M} \mathrm{Ca}^{2+}$ for PPADS and suramin, respectively; Table 2) and in shifting the $\mathrm{EC}_{50}$ value (from 1.5 to $44.4 \mu \mathrm{M}$ and to $132 \mu \mathrm{M}$, for suramin and PPADS, respectively; Fig. $8 D$ ).

These results showing that the blockade of $\mathrm{P} 2$ receptors by PPADS and suramin is different in WT and in Cx43 KO astrocytes further support the data described above indicating that WT and Cx43 KO spinal cord astrocytes express different P2 receptor subtypes. Furthermore, they indicate that the differential sensitivity of the two P2 receptor subtypes to ATP may account for the changes in calcium wave properties observed between WT and $\mathrm{Cx} 43 \mathrm{KO}$ spinal cord astrocytes.

\section{Purinoceptors also are altered in Cx43 KO astrocytes from the brain}

Because the data described above indicated that deletion of the $\mathrm{Cx} 43$ gene resulted in a change in $\mathrm{P} 2$ receptor subtype expression in spinal cord astrocytes, we evaluated whether such alteration also occurred in astrocytes from the brain by analyzing the order of $\mathrm{P} 2$ agonist potency in these cells.

In contrast to WT spinal cord astrocytes, WT brain astrocytes exhibited an order of agonist potency $(\mathrm{ATP}=\mathrm{UTP}>2-\mathrm{Me}-\mathrm{S}$ $\mathrm{ATP}=\mathrm{ADP}-\beta-S)$ suggesting that these cells express $\mathrm{P} 2 \mathrm{Y} 2$ receptors (Fig. 9A). Although the $\mathrm{EC}_{50}$ values differed somewhat, this order of agonist potency for WT brain astrocytes was the same as that obtained for Cx43 KO spinal cord astrocytes (compare Figs. $8 B, 9 A$ and values in Table 2). For $\mathrm{Cx} 43 \mathrm{KO}$ brain astrocytes the order of agonist potency obtained (ADP- $\beta-S>$ $\mathrm{UTP}>$ ATP $\gg 2$-Me-S-ATP; Fig. 9B) resembled that described for the P2Y3 purinoceptors in chick brain (Webb et al., 1996).

Although the order of $\mathrm{P} 2$ agonist potency was different in brain astrocytes cultured from $\mathrm{WT}$ and $\mathrm{Cx} 43 \mathrm{KO}$ mice, the $\mathrm{EC}_{50}$ values obtained for ATP and UTP were very similar $\left(\mathrm{EC}_{50}=3-5 \mu \mathrm{M}\right.$ in WT and $\mathrm{EC}_{50}=3-12 \mu \mathrm{M}$ in $\mathrm{Cx} 43 \mathrm{KO}$ astrocytes; Fig. 9A,B). Thus, in terms of the propagation of intercellular calcium waves through the extracellular space, it seems likely that expression of either of these two $\mathrm{P} 2 \mathrm{Y}$ receptors would affect wave propagation in a similar way.

\section{DISCUSSION}

It is shown here that spinal cord astrocytes form a weakly coupled syncytium, with functional gap junction channels formed by $\mathrm{Cx} 43$ and other connexins. The strength of coupling, measured as the junctional conductance between cell pairs $(3 \mathrm{nS})$, is four to six times lower than that described for cortical astrocytes [in rats, 13 nS, Dermietzel et al. (1991); in mouse, 17 nS, Spray et al. (1998)]; this difference is expected to reflect on the functionality of the astrocytic syncytium, specifically in the dissipation of ionic gradients, neurotransmitters, and metabolites. Furthermore, based on the values of junctional conductance $(\sim 1 \mathrm{nS})$ obtained here for pairs of $\mathrm{Cx} 43 \mathrm{KO}$ spinal cord astrocytes (compared with $3 \mathrm{nS}$ obtained for WT spinal cord astrocytes; see Fig. 1), it is estimated that approximately two-thirds of the total coupling is attributable to $\mathrm{Cx} 43$ and that the other connexins contribute the remaining one-third of coupling. This is strikingly different from the 5\% contribution calculated for connexins other than $\mathrm{Cx} 43$ in cortical astrocytes (Spray et al., 1998), signifying that the contribution of other connexins to astrocytic syncytial properties is more significant and important in the spinal cord than in the brain. The voltage sensitivities and single-channel properties of gap junctions between $\mathrm{Cx} 43 \mathrm{KO}$ spinal cord astrocytes are similar to those for Cx26, Cx30, Cx40, and Cx45 (Bukauskas et al., 1995a,b; Moreno et al., 1995; Hellmann et al., 1996; Valiunas et al., 1999), and the presence of these connexins has been confirmed in spinal cord 


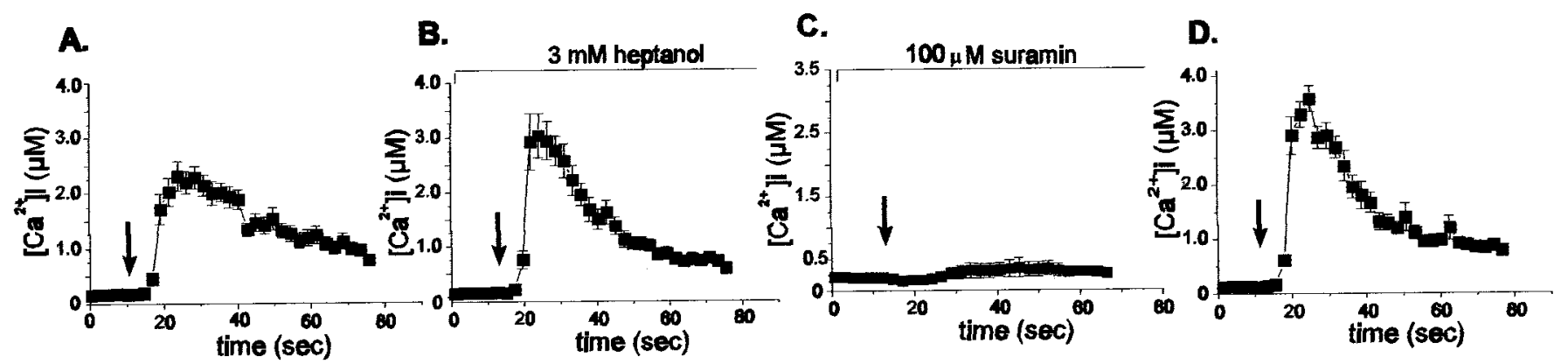

Figure 6. Changes in intracellular calcium levels in fura-2 AM-loaded WT astrocytes exposed to $5 \mu \mathrm{M}$ ATP before $(A)$ and after $(B)$ exposure to the gap junction channel blocker heptanol and to the P2 receptor antagonist suramin $(C)$. Note that heptanol ( 3 mM) did not attenuate the effect of ATP (compare $A$ and $B$ ), whereas suramin $(100 \mu \mathrm{M})$ greatly diminished the response $(C)$, which was reestablished 5 min after washout $(D) . n=60$ cells from two independent experiments. Arrows indicate times of ATP addition.

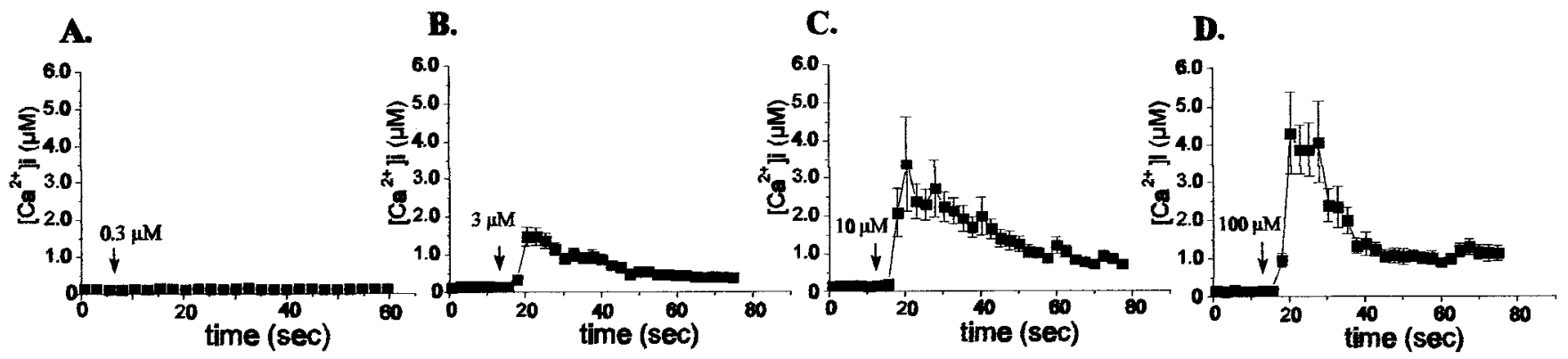

Figure 7. Intracellular calcium levels measured in WT astrocytes loaded with fura- $2 \mathrm{AM}$ in response to increasing ATP concentrations. $n=20$ cells in each panel.

Table 2. Maximal $\mathrm{Ca}^{2+}$ responses (in $\left.\mu \mathrm{M}\right)$ of spinal cord astrocytes to $\mathrm{P2}$ agonists

\begin{tabular}{|c|c|c|c|c|c|c|c|c|c|c|c|c|}
\hline \multirow{2}{*}{$\begin{array}{l}\text { [Agonist] } \\
(\mathrm{M})\end{array}$} & \multicolumn{2}{|c|}{ ATP } & \multicolumn{2}{|c|}{ UTP } & \multicolumn{2}{|l|}{$\mathrm{MeS}$} & \multicolumn{2}{|c|}{$\mathrm{ADP} \beta S$} & \multicolumn{2}{|c|}{ ATP-suramin } & \multicolumn{2}{|c|}{ ATP-PPADS } \\
\hline & WT & $\mathrm{KO}$ & WT & $\mathrm{KO}$ & WT & $\mathrm{KO}$ & WT & $\mathrm{KO}$ & WT & $\mathrm{KO}$ & WT & $\mathrm{KO}$ \\
\hline $10^{-8}$ & _ & 0.0 & _ & 0.0 & _ & _- & 0.0 & _ & & & & \\
\hline $3 \times 10^{-8}$ & - & 0.01 & - & 0.02 & - & $\overline{0} .02$ & & - & & & & \\
\hline $10^{-7}$ & - & 0.07 & - & 0.3 & $\overline{0} .2$ & 0.05 & 0.03 & - & & & & \\
\hline $3 \times 10^{-7}$ & $\overline{0} .0$ & 0.4 & - & 0.4 & 0.4 & - & 0.02 & - & & & & \\
\hline $10^{-6}$ & _ & 1.5 & 0.08 & 0.4 & _ & - & 0.09 & $\overline{0} .01$ & 0.0 & 0.03 & 0.04 & - \\
\hline $3 \times 10^{-6}$ & $\overline{1.4}$ & 1.7 & - & 1.2 & $\overline{0.9}$ & - & _ & _ & 0.04 & - & 0.08 & - \\
\hline $10^{-5}$ & 3.2 & _- & - & & 0.9 & $\overline{0} .06$ & $\overline{0.4}$ & $\overline{0} .1$ & 0.3 & $\overline{0} .09$ & 0.3 & - \\
\hline $3 \times 10^{-5}$ & - & - & $\overline{0} .7$ & & _ & - & 0.9 & 0.2 & 0.5 & - & 0.4 & - \\
\hline $10^{-4}$ & $\overline{4} .1$ & $\overline{1.9}$ & 1.4 & & - & $\overline{0} .2$ & 1.0 & 0.3 & 0.4 & $\overline{0} .2$ & 0.4 & $\overline{0.05}$ \\
\hline $3 \times 10^{-4}$ & _ & - & 1.5 & & - & 0.5 & _ & 0.9 & 0.4 & 0.2 & _- & 0.09 \\
\hline $10^{-3}$ & - & - & _- & & - & 1.6 & $\overline{1.7}$ & 1.2 & _- & 0.3 & - & 0.1 \\
\hline
\end{tabular}

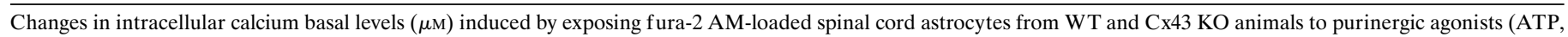

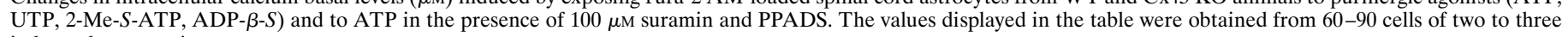
independent experiments.

astrocytes via RT-PCR, Northern blots, and immunocytochemistry (E. Scemes, unpublished observations). Because Cx43 forms nonselective channels whereas $\mathrm{Cx} 26, \mathrm{Cx} 40$, and $\mathrm{Cx} 45$ are more permissive to the transfer of cations than anions (Veenstra et al., 1994; Beblo et al., 1995; Beblo and Veenstra, 1997; Wang and Veenstra, 1997) (see also Spray, 1996), it is expected that the spinal cord astrocytic syncytium in $\mathrm{Cx} 43$ knock-outs will favor the exchange of positively charged molecules in comparison to what occurs in cortical astrocytes from these animals. Thus, it could be speculated that even weak coupling through cation-favoring channels will facilitate the dissipation of $\mathrm{K}^{+}$ions throughout the spinal cord astrocytic syncytium, whereas the limited diffusion of anionic signaling molecules, such as $\mathrm{IP}_{3}$, may compromise coordination of the network via gap junction-mediated propagation of calcium waves.

However, although the spinal cord astrocytic syncytium is less well coupled than that of the brain, the velocity, amplitude, and efficacy of calcium wave propagation between WT spinal cord astrocytes do not differ from that previously described for cortical astrocytes (Scemes et al., 1998). This suggests either that (1) the degree of coupling in spinal cord astrocytes is sufficient to allow the diffusion of second messengers to support wave propagation or (2) the extracellular pathway plays an important role in calcium wave propagation within the astrocytic syncytium. The first pos- 


\section{A. WILD TYPE}

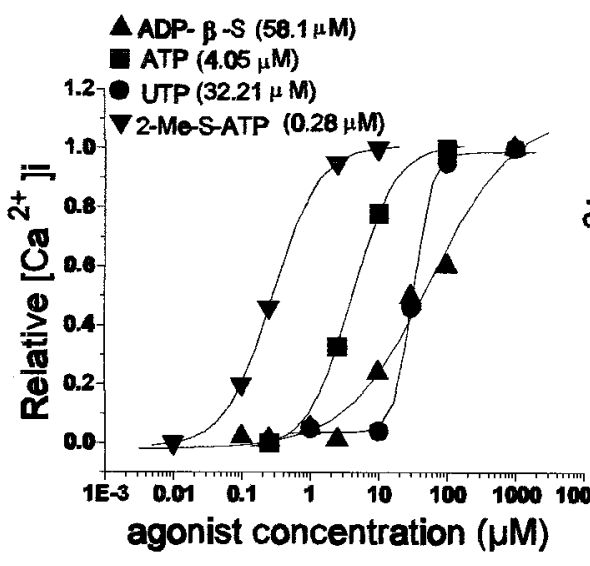

C. WILD TYPE

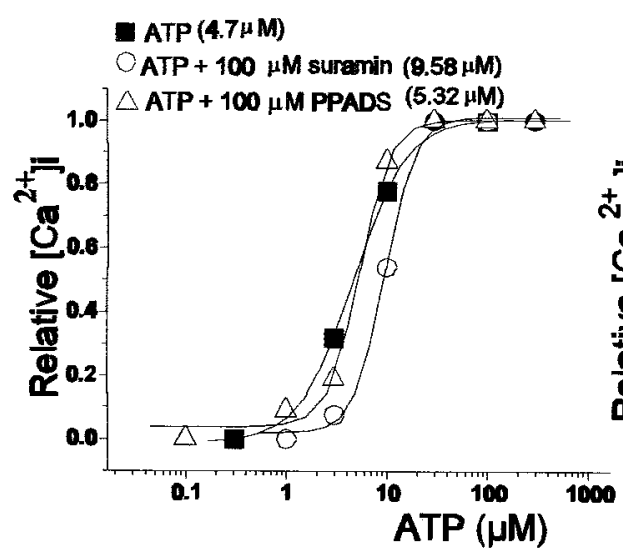

B. $\mathrm{Cx} 43 \mathrm{KO}$

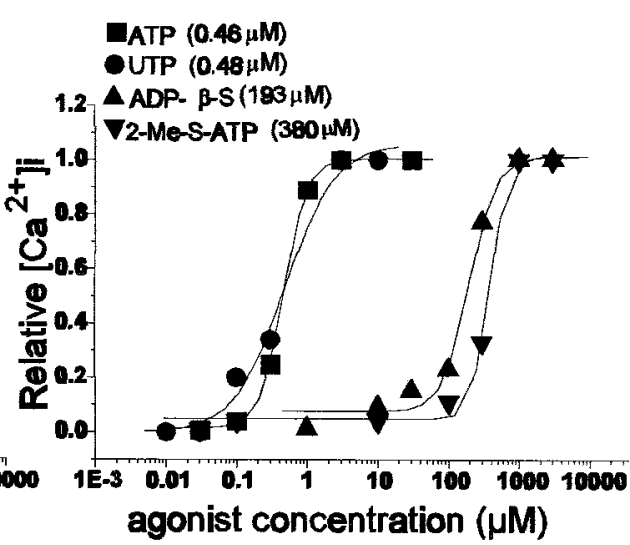

D. $\mathrm{Cx} 43 \mathrm{KO}$

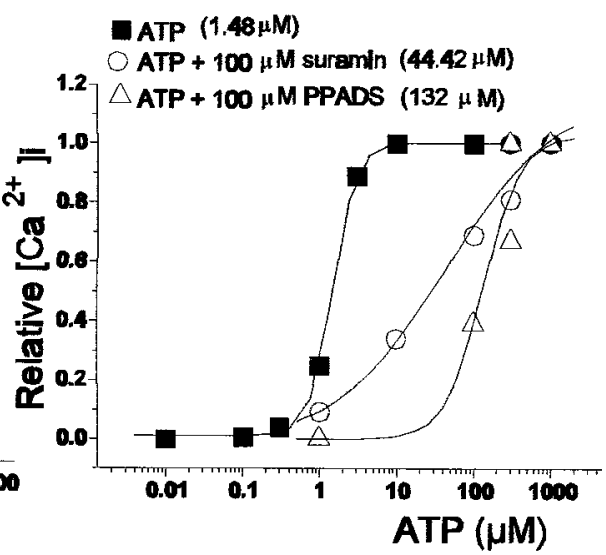

Figure 8. Dose-response curves obtained for $\mathrm{P} 2$ agonists $(A, B)$ and for ATP in the presence of two $\mathrm{P} 2$ antagonists $(C, D)$, suramin and PPADS, measured in fura-2 AM-loaded WT $(A, C)$ and $\mathrm{Cx} 43 \mathrm{KO}(B, D)$ spinal cord astrocytes. The order of agonist potency $(2-\mathrm{Me}-S$-ATP $>$ ATP $>$ UTP $\geq$ $\mathrm{ADP}-\beta-S$ ) measured by the $\mathrm{EC}_{50}$ values indicates that WT spinal cord astrocytes express a P2Y1 receptor subtype $(A)$; the order of potency $\mathrm{ATP}=\mathrm{UTP} \gg 2-\mathrm{Me}-S$-ATP $\geq$ ADP- $\beta-S$ indicates that $\mathrm{Cx} 43 \mathrm{KO}$ spinal cord astrocytes express a $\mathrm{P} 2 \mathrm{Y} 2$ receptor subtype $(B)$. Note that in WT astrocytes suramin and PPADS $(100 \mu \mathrm{M})$ did not affect the $\mathrm{EC}_{50}$ value obtained for ATP $(C)$, whereas in $\mathrm{Cx} 43$ $\mathrm{KO}$ astrocytes the dose-response curve to ATP was shifted to the right $(D)$. Each point in the graphs corresponds to the relative increment in intracellular calcium (from basal levels to maximal responses; see also Table 2) induced by increased concentrations of agonists. The results are from $60-80$ cells in at least three independent experiments. sibility is supported by the results obtained here showing that heptanol prevented calcium wave propagation between WT spinal cord astrocytes (see Table 1) and that this gap junction channel blocker does not affect the extracellular component of the wave, as seen by the responses of astrocytes to ATP when in the presence of heptanol (see Fig. 6). Taken together, these data support previous studies indicating that gap junction channels are the main, although not the exclusive, route for calcium wave propagation between astrocytes (Charles et al., 1992; Enkvist and McCarthy, 1992; Venance et al., 1995; Naus et al., 1997; Scemes et al., 1998).

The most surprising finding obtained in this study is that astrocytes from $\mathrm{Cx} 43$ null mice displayed altered functional expression of P2Y receptor subtypes. For intercellular communication within the spinal cord the shift in $\mathrm{P} 2 \mathrm{Y}$ receptor subtype from $\mathrm{P} 2 \mathrm{Y} 1$ to P2Y2 observed in Cx43 KO cells renders the extracellular component of calcium waves the main route by which calcium signaling is achieved. Because the P2Y2 receptor subtype expressed in $\mathrm{Cx} 43 \mathrm{KO}$ spinal cord astrocytes is one to two orders of magnitude more sensitive to ATP and UTP than the P2Y1 receptor expressed in the WT sibling cells (see $\mathrm{EC}_{50}$ values in Table 2 and Fig. 8), it is proposed that the same amount of ATP released from the stimulated cells would be sufficient to activate receptors in cells located much farther from the point of stimulation than would occur in WT cells expressing the less-sensitive P2Y1 receptor subtype. Such supposition is supported by the present results showing that the properties of calcium wave propagation between $\mathrm{Cx} 43 \mathrm{KO}$ spinal cord astrocytes are similar to those of WT sibling cells and that waves in Cx43 cells are greatly reduced by PPADS, a P2 receptor antagonist. For calcium waves traveling between brain astrocytes, however, the change in P2 receptor subtype from $\mathrm{P} 2 \mathrm{Y} 2$ to $\mathrm{P} 2 \mathrm{Y} 3$ is unlikely to have such an effect, because they display the same $\mathrm{EC}_{50}$ values for ATP and UTP (see Fig. 9). Thus, the extent of diffusion of ATP or UTP through the extracellular space is not expected to exceed the distance of second messenger diffusion through gap junctions. Indeed, attenuation of calcium wave propagation between $\mathrm{Cx} 43$ KO cortical astrocytes was reported previously (Scemes et al., 1998).

Although gap junctions may provide the main route by which astrocytes communicate with one another, it is clear that the extent to which junctional channels contribute to the propagation of intercellular calcium waves may vary in different CNS regions and under certain pathological conditions. For instance, the extent to which calcium waves propagate between cultured astrocytes derived from hypothalamus is one-half of that obtained for hippocampal astrocytes, although their strength of coupling appears to be similar (Blomstrand et al., 1999). Under pathological conditions, such as inflammation and neurodegenerative disorders of the CNS, the relative contribution of gap junctiondependent and independent mechanisms to the propagation of intercellular calcium waves may be altered; treatment of human fetal astrocytes with interleukin- $1 \beta$ shifts the mode of intercellular calcium wave propagation from a gap junction-dependent to a gap junction-independent mechanism that is paralleled by a de- 

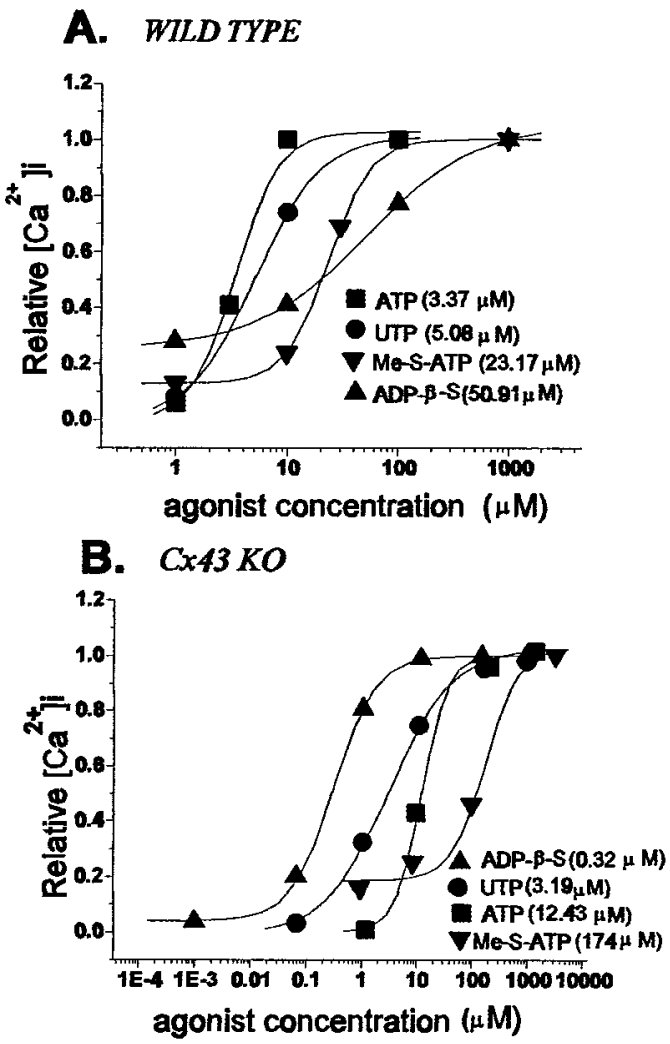

Figure 9. Dose-response curves obtained for $\mathrm{P} 2$ receptor agonists measured in fura-2 AM-loaded WT $(A)$ and $\mathrm{Cx} 43 \mathrm{KO}(B)$ brain astrocytes. Based on the $\mathrm{EC}_{50}$ values obtained for ATP, UTP, 2-Me-S-ATP, and ADP- $\beta-S$, the order of agonist potency indicates that WT brain astrocytes express $\mathrm{P} 2 \mathrm{Y} 2$, whereas $\mathrm{Cx} 43 \mathrm{KO}$ brain astrocytes express the P2Y3 receptor subtype. Each point in the graphs corresponds to the relative increment in intracellular calcium (from basal levels to maximal responses) induced by increased concentrations of agonists. The results were obtained from $60-80$ cells in at least three independent experiments.

crease in Cx43 expression and an increase in mRNA encoding the UTP-sensitive P2Y2 receptor (John et al., 1999).

Such an interplay between gap junctions and paracrine/autocrine signaling provides a high degree of plasticity for intercellular communication between astrocytes. Although we interpret our results to suggest that this interplay may reflect the influence of gap junctional communication on expression patterns of other genes, the mechanism by which $\mathrm{Cx} 43$ and $\mathrm{P} 2$ receptor expression is linked is unknown. One possible way by which this might occur would involve the different selective diffusion of signaling molecules through gap junction channels formed of different connexins. Such a mechanism recently was proposed for osteoblastic cell lines in which transcriptional activities of osteoblast-specific promoters were modulated in opposite directions by overexpressing either Cx43 or Cx45 (Lecanda et al., 1998). Alternatively, the expression of $\mathrm{Cx} 43$ might recruit a specific type of $\mathrm{P} 2$ receptor to the membrane preferentially (as occurs via the direct binding of ZO-1; Giepmans and Moolenaar, 1998; Toyof uku et al., 1998) or selectively might affect $\mathrm{P} 2$ receptor gene expression directly or via a binding protein.

The different $\mathrm{P} 2$ receptor subtypes functionally expressed in brain and spinal cord astrocytes and the different $\mathrm{P} 2$ receptor subtypes exhibited when $\mathrm{Cx} 43$ is absent provide further evidence that the physiological properties of astrocytes in these CNS regions are not identical. In terms of intercellular communication through calcium waves, such differences between brain and spinal cord astrocytes are likely to affect the extent to which the coordination of cooperative cell activity is achieved under normal and pathological conditions.

\section{REFERENCES}

Attwell D (1994) Glia and neurons in dialogue. Nature 369:707-708.

Batter DK, Corpina RA, Roy C, Spray DC, Hertzberg EL, Kessler JA (1992) Heterogeneity in gap junction expression in astrocytes cultured from different brain regions. Glia 6:213-221.

Beblo DA, Veenstra RD (1997) Monovalent cation permeation through the connexin 40 gap junction channel, $\mathrm{Cs}^{+}, \mathrm{Rb}^{+}, \mathrm{K}^{+}, \mathrm{Li}^{+}, \mathrm{TEA}$, TMA, TBA, and effects of anions $\mathrm{Br}^{-}, \mathrm{Cl}^{-}, \mathrm{F}^{-}$, acetate, aspartate, glutamate, and NO3. J Gen Physiol 109:509-522.

Beblo DA, Wang HZ, Beyer EC, Westphale EM, Veenstra RD (1995) Unique conductance, gating, and selective permeability properties of gap junction channels formed by connexin40. Circ Res 77:813-822.

Blomstrand F, Aberg ND, Eriksson PS, Hansson E, Ronnback L (1999) Extent of intercellular calcium wave propagation is related to gap junction permeability and level of connexin-43 expression in astrocytes in primary cultures from four brain regions. Neuroscience 92:255-265.

Bolego C, Ceruti S, Brambilla R, Puglisi L, Cattabeni F, Burnstock G, Abbracchio MP (1997) Characterization of the signaling pathways involved in ATP and basic fibroblast growth factor-induced astrogliosis. Br J Pharmacol 121:1692-1699.

Bukauskas FF, Elfgang C, Willecke K, Weingart R (1995a) Biophysical properties of gap junction channels formed by mouse connexin40 in induced pairs of transfected human $\mathrm{HeLa}$ cells. Biophys J 68:2289-2298

Bukauskas FF, Elfgang C, Willecke K, Weingart R (1995b) Heterotypic gap junction channels (connexin26-connexin32) violate the paradigm of unitary conductance. Pflügers Arch 429:870-872.

Charles AC, Merrill JE, Dirksen ER, Sanderson MJ (1991) Intercellular signaling in glial cells: calcium waves and oscillations in response to mechanical stimulation and glutamate. Neuron 6:983-992.

Charles AC, Naus CC, Zhu D, Kidder GM, Dirksen ER, Sanderson MJ (1992) Intercellular calcium signaling via gap junctions in glioma cells. J Cell Biol 118:195-201.

Charles AC, Kodali SK, Tyndale RF (1996) Intercellular calcium waves in neurons. Mol Cell Neurosci 7:337-353.

Christ GJ, Moreno AP, Melman A, Spray DC (1992) Gap junctionmediated intercellular diffusion of $\mathrm{Ca}^{2+}$ in cultured human corporal smooth muscle cells. Am J Physiol 263:C373-C383.

Churchill G, Louis C (1998) Roles of $\mathrm{Ca}^{2+}$, inositol trisphosphate, and cyclic ADP-ribose in mediating intercellular $\mathrm{Ca}^{2+}$ signaling in sheep lens cells. J Cell Sci 111:1217-1225.

Cornell-Bell AB, Finkbeiner SM (1991) $\mathrm{Ca}^{2+}$ waves in astrocytes. Cell Calcium 12:185-204.

Cornell-Bell AH, Williamson A (1993) Glutamate-induced hyperexcitability of astrocytes and neurons in epileptic cortex associated with tumors. In: Biology and pathology of astrocyte-neuron interactions (Fedoroff S, Burnstock G, eds), pp 51-65. New York: Plenum.

Cornell-Bell AH, Finkbeiner SM, Cooper MS, Smith SJ (1990) Glutamate induces calcium waves in cultured astrocytes: long-range glial signaling. Science 247:470-473.

Cotrina ML, Liu JH, Alves-Rodrigues A, Liu S, Li J, Azmi-Ghadimi H, Kang J, Naus CC, Nedergaard M (1998) Connexins regulate calcium signaling by controlling ATP release. Proc Natl Acad Sci USA 95:15735-15740.

Dermietzel R (1996) Molecular diversity and plasticity of gap junctions in the nervous system. In: Gap junctions in the nervous system (Spray DC, Dermietzel R, eds), pp 39-60. Houston: Landes.

Dermietzel R, Hertzberg EL, Kessler JA, Spray DC (1991) Gap junctions between cultured astrocytes: immunocytochemical, molecular, and electrophysiological analysis. J Neurosci 11:1421-1432.

Dermietzel R, Gao Y, Scemes E, Vieira D, Urban M, Kremer M, Bennett MVL, Spray DC (2000) Connexin43 null $[\mathrm{Cx} 43(-/-)]$ mice reveal that astrocytes express multiple connexins. Brain Res Rev, in press.

Enkvist MO, McCarthy KD (1992) Activation of protein kinase C blocks astroglial gap junction communication and inhibits the spread of calcium waves. J Neurochem 59:519-526.

Finkbeiner S (1992) Calcium waves in astrocytes-filling in the gaps. Neuron 8:1101-1108. 
Giepmans BN, Moolenaar WH (1998) The gap junction protein connexin43 interacts with the second PDZ domain of the zona occludens-1 protein. Curr Biol 8:931-934.

Grynkiewicz G, Poenie M, Tsien RY (1985) A new generation of $\mathrm{Ca}^{2+}$ indicators with greatly improved fluorescence properties. J Cell Biol 260:3440-3450.

Guan X, Cravatt BF, Ehring GR, Hall JE, Boger DL, Lerner RA, Gilula NB (1997) The sleep-inducing lipid oleomide deconvolutes gap junction communication and calcium wave transmission in glial cells. J Cell Biol 139:1785-1792.

Guthrie PB, Knappenberger J, Segal M, Bennett MVL, Charles AC, Kater SB (1999) ATP released from astrocytes mediates glial calcium waves. J Neurosci 19:520-528.

Hassinger TD, Guthrie PB, Atkinson PB, Bennett MV, Kater SB (1996) An extracellular component in propagation of astrocytic calcium waves. Proc Natl Acad Sci USA 93:13268-13273.

Hellmann P, Winterhager E, Spray DC (1996) Properties of connexin40 gap junction channels endogenously expressed and exogenously overexpressed in human choriocarcinoma cell lines. Pflügers Arch 432:501-509.

Ho C, Hicks J, Salter MW (1995) A novel P2 purinoceptor expressed by a subpopulation of astrocytes from the dorsal spinal cord of the rat. $\mathrm{Br} \mathbf{J}$ Pharmacol 116:2909-2918.

John GR, Scemes E, Suadicani SO, Liu JS, Charles PC, Lee SC, Spray DC, Brosnan CF (1999) Interleukin- $1 \beta$ differentially regulates calcium wave propagation between primary human fetal astrocytes via pathways involving P2 receptors and gap junction channels. Proc Natl Acad Sci USA 98:11613-11618.

Kandler K, Katz LC (1995) Neuronal coupling and uncoupling in the developing nervous system. Curr Opin Neurobiol 5:98-105.

Kandler K, Katz LC (1998) Coordination of neuronal activity in developing visual cortex by gap junction-mediated biochemical communication. J Neurosci 18:1419-1427.

King BF, Neary JT, Zhu Q, Wang S, Norenberg MD, Burnstock G (1996) P2 purinoceptors in rat cortical astrocytes: expression, calciumimaging, and signaling studies. Neuroscience 74:1187-1196.

Kunzelmann P, Schroder W, Traub O, Steinhauser C, Dermietzel R, Willecke K (1999) Late onset and increasing expression of the gap junction protein connexin30 in adult murine brain and long-term cultured astrocytes. Glia 25:111-119.

Lecanda F, Towler DA, Ziambaras K, Cheng SL, Koval M, Steinberg TH, Civitelli R (1998) Gap junctional communication modulates gene expression in osteoblastic cells. Mol Biol Cell 9:2249-2258.

Lee SH, Kim WT, Cornell-Bell AH, Sontheimer H (1994) Astrocytes exhibit regional specificity in gap junction coupling. Glia 11:315-325.

Moreno AP, Rook MB, Fishman GI, Spray DC (1994a) Gap junction channels: distinct voltage-sensitive and -insensitive conductance states. Biophys J 69:113-119.

Moreno AP, Saez JC, Fishman GI, Spray DC (1994b) Human connexin43 gap junction channels. Regulation of unitary conductance by phosphorylation. Circ Res 74:1050-1057.

Moreno AP, Laing JG, Beyer EC, Spray DC (1995) Properties of gap junction channels formed of connexin 45 endogenously expressed in human hepatoma (SKHep1) cells. Am J Physiol 268:C356-C365.

Naus CC, Bechberger JF, Zhang Y, Venance L, Yamasaki H, Juneja SC, Kidder GM, Giaume C (1997) Altered gap junctional communication, intercellular signaling, and growth in cultured astrocytes deficient in connexin43. J Neurosci Res 49:528-540.

Nedergaard M (1994) Direct signaling from astrocytes to neurons in cultures of mammalian brain cells. Science 263:1768-1771.

Nedergaard M, Cooper AJ, Goldman SA (1995) Gap junctions are required for the propagation of spreading depression. J Neurobiol 28:433-444.

Ochalski PA, Frankenstein UN, Hertzberg EL, Nagy JI (1997) Connexin43 in rat spinal cord: localization and identification of heterotypic astro-oligodendrocytic gap junctions. Neuroscience 76:931-945.
Osipchuk Y, Cahalan M (1992) Cell-to-cell spread of calcium signals mediated by ATP receptors in mast cells. Nature 359:241-244.

Pearce B, Langley D (1994) Purine- and pyrimidine-stimulated phosphoinositide breakdown and intracellular calcium mobilization in astrocytes. Brain Res 660:329-332.

Ralevic V, Burnstock G (1998) Receptors for purines and pyrimidines. Pharmacol Rev 50:413-492.

Rash JK, Yasumura T (1999) Direct immunogold labeling of connexin and aquaporin-4 in freeze-fracture replicas of liver, brain, and spinal cord: factors limiting quantitative analysis. Cell Tissue Res 296:307-321.

Saez JC, Connor JA, Spray DC, Bennett MVL (1989) Hepatocyte gap junctions are permeable to the second messenger, inositol 1,4,5trisphosphate, and to calcium ions. Proc Natl Acad Sci USA 86:2708-2712.

Salter MW, Hicks JL (1994) ATP-evoked increases in intracellular calcium in neurons and glia from the dorsal spinal cord. J Neurosci 14:1563-1575.

Salter MW, Hicks JL (1995) ATP causes release of intracellular $\mathrm{Ca}^{2+}$ via the phospholipase $\mathrm{C} \beta / \mathrm{IP}_{3}$ pathway in astrocytes from the dorsal spinal cord. J Neurosci 15:2961-2971.

Sanderson MJ, Charles AC, Boitano S, Dirksen ER (1994) Mechanisms and function of intercellular calcium signaling. Mol Cell Endocrinol 98:173-197.

Scemes E, Dermietzel R, Spray DC (1998) Calcium waves between astrocytes from Cx43 knock-out mice. Glia 24:65-73.

Spray DC (1996) Physiological properties of gap junction channels. In: Gap junctions in the nervous system (Spray DC, Dermietzel R, eds), pp 39-60. Houston: Landes.

Spray DC, Harris AL, Bennett MV (1981) Equilibrium properties of a voltage-dependent junctional conductance. J Gen Physiol 77:77-93.

Spray DC, Vink MJ, Scemes E, Suadicani SO, Fishman GI, Dermietzel R (1998) Characteristics of coupling in cardiac myocytes and CNS astrocytes cultured from wild-type and Cx43-null mice. In: Gap junctions (Werner R, ed), pp 281-285. Netherlands: IOS.

Takeda M, Nelson DJ, Soliven B (1995) Calcium signaling in cultured rat oligodendrocytes. Glia 14:225-236.

Theriault E, Frankenstein UN, Hertzberg EL, Nagy JI (1997) Connexin43 and astrocytic gap junctions in the rat spinal cord after acute compression injury. J Comp Neurol 382:199-214.

Toyofuku T, Yabuki M, Otsu K, Kuzuya T, Hori M, Tada M (1998) Direct association of the gap junction protein connexin- 43 with ZO-1 in cardiac myocytes. J Biol Chem 273:12725-12731.

Valiunas V, Manthey D, Vogel R, Willecke K, Weingart R (1999) Biophysical properties of mouse connexin30 gap junction channels studied in transfected human HeLa cells. J Physiol (Lond) 519:631-644.

Veenstra RD, Wang HZ, Beyer EC, Brink PR (1994) Selective dye and ionic permeability of gap junction channels formed by connexin 45. Circ Res 75:483-490.

Venance L, Piomelli D, Glowinski J, Giaume C (1995) Inhibition by anandamide of gap junctions and intercellular calcium signaling in striatal astrocytes. Nature 376:590-594.

Venance L, Stella N, Glowinski J, Giaume C (1997) Mechanism involved in initiation and propagation of receptor-induced intercellular calcium signaling in cultured rat astrocytes. J Neurosci 17:1981-1992.

Wang HZ, Veenstra RD (1997) Monovalent ion selectivity sequences of the rat connexin43 gap junction channel. J Gen Physiol 109:491-507.

Webb TE, Henderson D, King BF, Wang S, Simon J, Batenson AN, Burnstock G, Barnard EA (1996) A novel G-protein-coupled P2 purinoceptor (P2Y3) activated preferentially by nucleoside diphosphates. Mol Pharmacol 50:258-265.

Yuste R, Nelson DA, Rubin WW, Katz LC (1995) Neuronal domain in developing neocortex: mechanisms of coactivation. Neuron 14:7-17.

Zanotti S, Charles A (1997) Extracellular calcium sensing by glial cells: low extracellular calcium induces intracellular calcium release and intracellular signaling. J Neurochem 69:594-602. 